\title{
Insulin therapy in patients with COVID-19
}

\author{
Chia Siang Kow ${ }^{1,2}\left[\right.$ D $\cdot$ Dinesh Sangarran Ramachandram ${ }^{2} \cdot$ Syed Shahzad Hasan ${ }^{3,4}$
}

Received: 20 September 2021 / Accepted: 3 October 2021 / Published online: 14 October 2021

(c) Springer-Verlag Italia S.r.l., part of Springer Nature 2021

We are delighted with the publication of the narrative review by Avogaro and colleagues [1] which summarized the use of several antidiabetic therapies in patients with coronavirus disease 2019 (COVID-19). The review has provided evidence especially with regard to the safe use of metformin and dipeptidyl peptidase 4 (DPP-4) inhibitors, which had been associated with the concerns of increased severity of COVID-19, during the early days of the COVID-19 pandemic when evidence was lacking [2]. We believe that this should provide enough reassurance to the frontline clinicians who are managing patients with COVID-19 and concurrent type 2 diabetes. In addition, based on a thorough review of the literature, the authors outlined the treatment options for patients with COVID-19 and concurrent diabetes. In patients with severe/critical course of COVID-19, the authors' recommendations of basal-plus, basal-bolus, and intravenous insulin regimens coincide with the previous review [3].

However, we would like to bring to the attention that the sliding scale insulin regimen should not be disregarded as our armamentarium for managing hyperglycemia in hospitalized patients with COVID-19 and concurrent diabetes. The use of sliding scale insulin for the inpatient management of hyperglycemia has been controversial since it is deemed as a non-physiological glucose management strategy

Managed By Massimo Porta.

This comment refers to the article available online at https://doi. org/10.1007/s00592-021-01739-1.

Chia Siang Kow

chiasiang_93@hotmail.com

1 School of Postgraduate Studies, International Medical University, Kuala Lumpur, Malaysia

2 School of Pharmacy, Monash University Malaysia, Bandar Sunway, Subang jaya, Selangor, Malaysia

3 School of Applied Sciences, University of Huddersfield, Huddersfield, UK

4 School of Biomedical Sciences and Pharmacy, University of Newcastle, Callaghan, Australia compared to the basal-plus and basal-bolus insulin regimens. Despite the discouragement of using sliding scale insulin, a 2018 Cochrane review [4] reported that the currently available evidence is not sufficiently robust to recommend basalbolus insulin over sliding scale insulin for the management of hyperglycemia in hospitalized, non-critically ill patients.

We believe that in addition to the severity of COVID-19, the inpatient blood glucose levels should also be considered, when deciding the insulin regimen for hospitalized patients with COVID-19 and concurrent diabetes. The universal recommendation of basal-plus, basal-bolus, and intravenous insulin regimens for the management of hyperglycemia in hospitalized patients with COVID-19 may not be appropriate when blood glucose levels are not significantly elevated (i.e., $<10 \mathrm{mmol} / \mathrm{L}$ or $180 \mathrm{mg} / \mathrm{dL}$ ). The use of such intensive insulin regimens in hospitalized patients without significantly elevated blood glucose levels may lead to hypoglycemic events, which can have disastrous consequences.

In this population of patients, the use of sliding scale insulin can be adequate for managing hyperglycemia. As exemplified in a recent large observational study [5] of 25,813 hospitalized adult patients with type 2 diabetes, $85.0 \%$ of patients with admission blood glucose level of $<10 \mathrm{mmol} / \mathrm{L}(180 \mathrm{mg} / \mathrm{dL})$ demonstrated satisfactory blood glucose control (mean blood glucose during hospitalization $<10 \mathrm{mmol} / \mathrm{L}$ ) without hypoglycemia while receiving continuous sliding scale insulin throughout their hospitalization. Therefore, we opine that an individualized approach to the inpatient management of hyperglycemia in patients with COVID-19 is imperative, and judicious use of sliding scale insulin can be a viable option for patients without persistently and significantly elevated blood glucose levels.

Some clinicians may be concerned by the increased COVID-19-related mortality associated with the use of insulin therapy. However, as pointed out by the authors, the use of insulin therapy may identify patients with a more severe course of COVID-19, which can therefore confound such association. Hence, the use of insulin therapy should not be withheld in patients with COVID-19 who are appropriately indicated for its use, with periodic blood glucose 
monitoring in place to escalate/deescalate insulin therapy during hospitalization.

\section{Funding: None.}

\section{Declarations}

Conflict of interest The authors declare that they have no conflict of interest.

\section{References}

1. Avogaro A, Bonora B, Fadini GP (2021) Managing diabetes in diabetic patients with COVID: where do we start from? Acta Diabetol. https://doi.org/10.1007/s00592-021-01739-1
2. Kow CS, Hasan SS (2021) Use of DPP-4 inhibitors in patients with COVID-19. Acta Diabetol 58(2):245-246

3. Hasan SS, Kow CS, Bain A, Kavanagh S, Merchant HA, Hadi MA (2021) Pharmacotherapeutic considerations for the management of diabetes mellitus among hospitalized COVID-19 patients. Expert Opin Pharmacother 22(2):229-240

4. Colunga-Lozano LE, Gonzalez Torres FJ, Delgado-Figueroa N et al (2018) Sliding scale insulin for non-critically ill hospitalised adults with diabetes mellitus. Cochrane Database Syst Rev. https:// doi.org/10.1002/14651858.CD011296.pub2

5. Migdal AL, Fortin-Leung C, Pasquel F, Wang H, Peng L, Umpierrez GE (2021) Inpatient Glycemic Control With Sliding Scale Insulin in Noncritical Patients With Type 2 Diabetes: Who Can Slide? J Hosp Med 16(8):462-468

Publisher's Note Springer Nature remains neutral with regard to jurisdictional claims in published maps and institutional affiliations. 